\title{
Association between sensory function and medio-lateral knee position during functional tasks in patients with anterior cruciate ligament injury
}

\author{
Anna Cronström ${ }^{*}$ and Eva Ageberg
}

\begin{abstract}
Background: Patients with anterior cruciate ligament $(A C L)$ injury often exhibit reduced movement quality during functional tasks in the form of a knee-medial-to-foot position (KMFP). This movement pattern is suggested to be more common in women than in men, but the possible contributing sensorimotor factors for this altered knee position are poorly studied in these patients. The aim of this study was to evaluate the association between sensory function and medio-lateral knee position during functional tasks in men and women with ACL injury.

Methods: Fifty-one patients (23 women) aged 18-40 years with ACL injury were included in this cross-sectional study. Measures of sensory function were assessed by the threshold to detection of passive motion (TDPM) for knee kinesthesia and by the vibration perception threshold (VPT) for vibration sense. Movement quality was assessed by visual observation of the position of the knee relative to the foot during the following four functional tasks with different degrees of difficulty: the single-limb mini-squat, stair descending, the forward lunge, and the drop-jump. Spearman's rank correlation coefficient was used to determine the relationship between the sensory measures and the medio-lateral knee position during the functional tasks. Differences in TDPM and/or VPT between subjects with good and poor movement quality were evaluated using the independent $t$-test. Separate gender analyses were performed.

Results: Worse TDPM was associated with a KMFP during the drop jump in men. Worse VPT at the toe and ankle was associated with a KMFP during stair descending and the forward lunge in women, but no associations were found in men.

Conclusion: Worse kinesthesia, measured by TDPM, might be associated with KMFP during the drop jump in men with $A C L$ injury while worse vibration sense, measured by the VPT, at the foot and ankle might be related to KMFP in women. Further studies are needed to confirm these results.
\end{abstract}

Keywords: Proprioception, Sensory function, Kinematics, Anterior cruciate ligament, Movement quality

\section{Background}

It is well known that patients with ACL injury have decreased functional ability such as reduced muscle strength or a shorter hop distance with the injured leg compared to the non-injured leg as assessed by quantitative methods [1]. Moreover, one third of these patients will never get back to their pre-injury activity level [2]. Recent investigations report that these patients also exhibit poorer quality of movement during functional tasks as measured by changes in postural orientation

\footnotetext{
* Correspondence: anna.cronstrom@med.lu.se

Department of Health Sciences, Lund University, PO Box 157 SE-221 00 Lund, Sweden
}

[3-5]. Postural orientation is defined as the "ability to stabilize the body segments in relation to each other and the environment", for instance, keeping the trunk, hip, knee, and ankle in line during dynamic activity [6]. The medio-lateral knee position is commonly used to evaluate movement quality of the knee [7-9], and a knee-over-foot position (KOFP) reflects good movement quality while a knee-medial-to-foot position (KMFP) reflects poor movement quality. A KMFP during movements has been reported to be a risk factor for sustaining an ACL injury $[9,10]$ and to be related to a high re-injury rate $[11,12]$. Three-dimensional (3-D) motion analysis equipment is the gold standard for measuring medio-lateral knee 
position, but two-dimensional (2-D) motion analysis and visual observation and scoring are also used. The latter has moderate to high reliability $[4,7,8,13,14]$, is valid in $2-\mathrm{D}$ [7], and is an inexpensive method that is easy to use in both clinical settings and in large-scale studies [4,7].

Possible contributing factors for medio-lateral knee position in patients with ACL injury are not well studied, but such data would be helpful in the design of training regimes. In a previous study, no relation was found between quadriceps or hamstring muscle power and postural orientation during several different functional activities [3], and this indicates that factors other than muscle power contribute to the altered movement quality in these patients.

Sensory function in terms of knee proprioception is impaired after ACL injury [15]. Kinesthesia, measured as the threshold to detection of passive motion (TDPM) is commonly used to assess proprioception in patients with an ACL-deficient knee $[16,17]$. In a recent study, sense of vibration was evaluated as a measure of sensory function in patients with an ACL injury [18]. It was reported that worse proprioception is related to worse functional performance-as measured by the one-leg hop test for distance $[19,20]$ - and to poorer single-limb balance [21] in patients with ACL injury. Hence, proprioceptive acuity seems to be relevant for functional performance. Moreover, a previous study reported a relation between worse proprioception and reduced ability to control knee flexion during a single-leg stop jump task, in non-injured men, [22]. However, to our knowledge, the possible relation between sensory function and medio-lateral knee position during functional tasks has not been previously investigated. Because previous studies have found that a KMFP was more prevalent in women than in men during activity in both non-injured individuals [23-27] and in patients with ACL injury [5], it is important to analyze men and women separately.

The aim of this cross-sectional study was to investigate the association between sensory function-measured as kinesthesia and vibration sense-and medio-lateral knee position during functional tasks in patients with ACL injury. Possible gender differences were also explored. We hypothesized that worse sensory function would be related to a KMFP during functional tasks and that this relation would be more evident in women than in men.

\section{Methods}

\section{Subjects}

A convenience sample of 51 patients (23 women) ranging in age from 18 years to 40 years with arthroscopic or MRI-verified ACL injury or ACL reconstruction with or without associated injuries to the knee and currently undergoing neuromuscular training, supervised by physical therapists, were included (Table 1). Patients who used
Table 1 Characteristics of the subjects

\begin{tabular}{llll}
\hline Characteristic & $\begin{array}{l}\text { Women } \\
\text { (n= 23) }\end{array}$ & $\begin{array}{l}\text { Men } \\
\text { (n= 28) }\end{array}$ & p-value \\
\hline Age (years) a & $23(4.0)$ & $26(6.1)$ & $\mathbf{0 . 0 2 4}$ \\
BMla & $22.5(2.21)$ & $24.7(2.85)$ & $\mathbf{0 . 0 0 4}$ \\
Tegner activity score pre injury \# & $9(8-9)$ & $9(8-9)$ & 0.504 \\
Tegner activity score post injury \# & $3(2-6)$ & $4(3-7)$ & 0.274 \\
Injured right knee, $n$ (\%) & $11(48)$ & $20(71)$ & 0.089 \\
Time since injury, & $45(42.1)$ & $66(57.9)$ & 0.146 \\
non-reconstruction (weeks)a & & $19(68)$ & 0.234 \\
Reconstruction, $n$ (\%) & $19(83)$ & $47(52.5)$ & 0.474 \\
Time since reconstruction (weeks) 0 & $36(40.7)$ & $20(71)$ & 0.272 \\
Associated injuries, $n$ (\%) & $13(57)$ & $8(28.6)$ & 0.581 \\
Collateral ligament, $n$ (\%) & $5(22)$ & $16(57.1)$ & 0.160 \\
Meniscal, $n$ (\%) & $9(39)$ & $7(25)$ & 0.450 \\
Cartilage, $n$ (\%) & $8(35)$ & &
\end{tabular}

$a=$ mean (SD), \# = median (quartiles), bold text = statistically significant difference $(p \leq 0.05)$.

crutches, those who had finished their rehabilitation, and those with other injuries affecting function were excluded. Men were approximately 3 years older and had a higher BMI than women, but no other demographic differences were present (Table 1). All patients were recruited at sports physical therapy clinics in Skåne, Sweden, and gave their written informed consent to participate. The study was approved by the Advisory Committee for Research Ethics in Health Education at the Faculty of Medicine of Lund University (VEN 48-12).

\section{Assessment}

The measurements were taken in the order that they appear below. A 5-minute warm up on a stationary bike preceded the evaluation of the functional tasks. All subjects wore shorts and performed the single leg squat and stair descending barefoot. For the forward lunge and drop jump, the participants wore their training shoes for shock absorption. The sensory measures were taken by one investigator who was blinded to the movement quality scores. A consensus assessment was reached by two raters who were blinded to the sensory scores, and this was used to determine the medio-lateral knee position scores. Data for the injured leg were used in the analysis. The images in this study illustrate the methods used. These individuals were not included in the data collection. All gave their written consent to publish these images.

\section{Vibration sense}

The vibratory perception threshold (VPT) was measured with a biothesiometer [28-31] according to the manufacturer's instructions. The application button on the biothesiometer was held in such way that the weight of the machine provided the application button with a standard 
pressure. To make the subject familiar with the biothesiometer, it was tested on the subjects' processus styloideus ulna prior to the trials. The vibrator was then held to the subjects' most prominent point of the metatarsophalangeal joint 1 (MTP1), the medial malleolus (MM), and the medial femoral condyle (MF). The subjects lay in a supine position with their eyes closed and were told to indicate by raising their hand when any sensation of vibration was felt [31]. The amplitude was increased by 1 volt per second, and the voltage when the subject first felt any sensation of vibration was noted as the VPT. The mean of three subsequent measurements was calculated for statistics analysis. A higher value indicated worse VPT. High reliability ( $\mathrm{ICC}=0.96-0.99)$ for the biothesiometer has been reported [32].

\section{Kinesthesia}

Kinesthesia was measured by the TDPM on a specially designed platform as described previously [16] (Figure 1). The platform is mounted on a steel frame and has an electric motor with a wire mounted at the end. The subject lies on the platform in a lateral position with the lower leg in a plastic splint, and the splint is attached to a sled and connected to the wire that can make the splint move the knee in either flexion or extension. An analog scale at the end of the platform registers movements

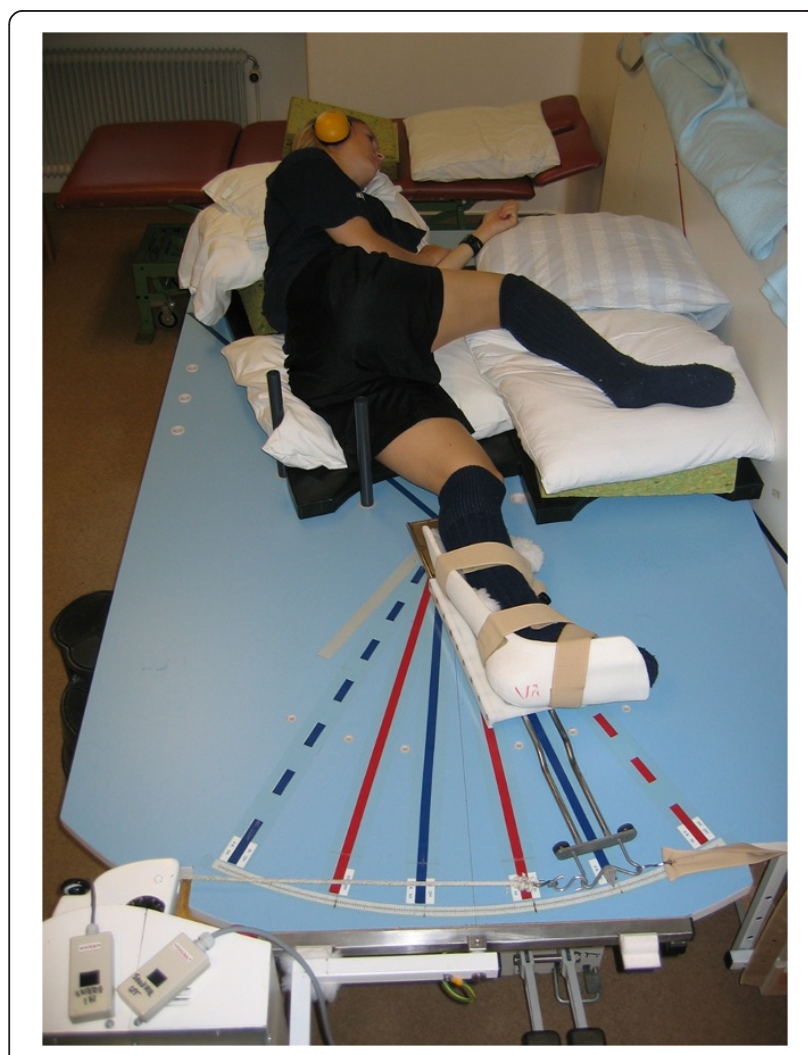

Figure 1 Kinesthesia testing device. in increments of $0.25^{\circ}$. In order to prevent any false experience of movements derived from the sound when the measuring device was started, all participants wore headphones and listened to a recording of the sound that was produced by the electric motor. The subjects were told to close their eyes and indicate by raising their hand when any movement in the knee was felt. TDPM was measured towards extension (TE) and flexion (TF) from a 20-degree starting position [16]. The median values of three consecutive measurements of TE20 and TF20 were determined, and an index value created from the sum of TE20 and TF20 was used for the statistical analysis. A higher value indicates poorer TDPM, and moderate reliability ( $\mathrm{ICC}=0.63-0.70)$ has previously been reported for this device [16].

\section{Movement quality}

Movement quality, in terms of postural orientation, was assessed by visual observation of a video recording of each trial. The raters were able to watch the video in slow motion and to review the movie as many times as needed. The position of the knee in relation to the foot was independently scored by two experienced assessors during four different functional tasks commonly used to assess medio-lateral knee position. The tasks included the single-limb mini squat [7], stair descending [33], the forward lunge [34], and the drop-jump [9] (Table 2). The knee position relative to the foot during the participant's performance of each task was assessed on an ordinal scale from 0 to 2 . If the mid-point of the patella was in line with or lateral to the second toe, a score of 0 = "good" was given for the movement quality. If the mid-point of the patella was medial to the second toe, a score of 1 = "fair" was given. Finally, if the mid-point of the patella was clearly placed medial to the first toe, a score of 2 = "poor" was given (Figure 2). Any disagreement was resolved by consensus discussion between the two raters. If required, the recording was viewed several times and/or in slow motion until consensus was reach. These movement quality assessments showed good to excellent agreement (ICC $=0.710-0.939$ ) (Table 3).

For safety reasons, subjects who had an ACL reconstruction less than six months prior to the test occasion or those whose physical therapist stated that they were not ready to jump were not permitted to perform the drop jump test. Subjects who were not able to perform the test were considered as missing values.

\section{Statistics}

All calculations were performed with SPSS statistics 20.0. There were no statistically significant correlations between patient demographics and the medio-lateral knee position or sensory variables $(p>0.05)$. Men and women were analyzed separately. Spearman's rank correlation 


\section{Table 2 Description of the functional tasks}

Single limb mini squat Performed according to Ageberg et al. [7] but without allowing fingertip support for maintaining balance. The patient is standing on one leg with the second toe placed on a marked longitudinal line. He/she is instructed to flex the injured knee until he/she cannot see the toes (approximately $50^{\circ}$ ) and then to return to extension. Repeated 5 times.

Stair descending

Performed according to Pfeifer et al. [33] and modified to use a step board $27 \mathrm{~cm}$ off the ground. The patient stands on the step board. He/she is instructed to step down to the floor with the non-injured leg and then return to the starting position. The injured leg, which is in contact with the step board throughout the entire movement, is evaluated. Repeated 5 times.

Forward lunge

Performed according to Alkjaer et al. [34]. The patient is standing with his/her feet hip-width apart on the floor. He/she is instructed to take a long stride forward, about $1 \mathrm{~m}$, with the injured leg and to flex the knee to approximately $90^{\circ}$ and then push back to the starting position by extending the front leg. Repeated 3 times.

Drop jump

Performed according to Hewett et al. [9] but modified to use the second landing instead of the first landing, because the second landing may better represent the situation when an ACL injury occur [35]. The patient stands on a step board $27 \mathrm{~cm}$ off the ground with the feet hip-width apart. He/she is instructed to drop from the step board and directly perform a maximal vertical jump. Arm swing is allowed during the jump. Repeated 3 times.

coefficient was used to determine the relationship between the sensory measures and the medio-lateral knee position during the functional tasks. The knee position scores were also dichotomized for each test; one group included subjects who were given a score of "0" (good movement quality), and one group included subjects who had been given a score of either " 1 " or " 2 " (poor movement quality). These values were used to evaluate any differences in TDPM and/or VPT between subjects with good and poor movement quality using the independent $t$-test. The independent $t$-test was also used to evaluate any gender difference in sensory function. The Mann-Whitney $U$-test was used to detect any differences in medio-lateral knee position between men and women. Because this was an exploratory study, we did not calculate the sample size a priori, nor did we apply corrections for multiple comparisons. A p-value less than or equal to 0.05 was considered statistically significant.

\section{Results}

All 51 subjects completed the tests of sensory function. Sixteen subjects were not able to perform all functional tasks, especially the forward lunge and the drop jump. There was no gender difference in medio-lateral knee position for any of the functional tasks (Table 4).

\section{Correlations between sensory function and movement quality}

Worse kinesthesia was associated with a KMFP during the drop jump in men $\left(\mathrm{r}_{\mathrm{s}}=0.423, \mathrm{p}=0.044\right)$ (Table 5). In women, worse vibration sense at MTP1 and MM was associated with a KMFP during stair descending $\left(r_{\mathrm{s}}=0.453\right.$, $\mathrm{p}=0.034$ for MTP1, and $\mathrm{r}_{\mathrm{s}}=0.626, \mathrm{p}=0.002$ for $\mathrm{MM}$ ), and worse vibration sense at MM was associated with a KMFP during the forward lunge $\left(\mathrm{r}_{\mathrm{s}}=0.544, \mathrm{p}=0.016\right)$ (Table 5).
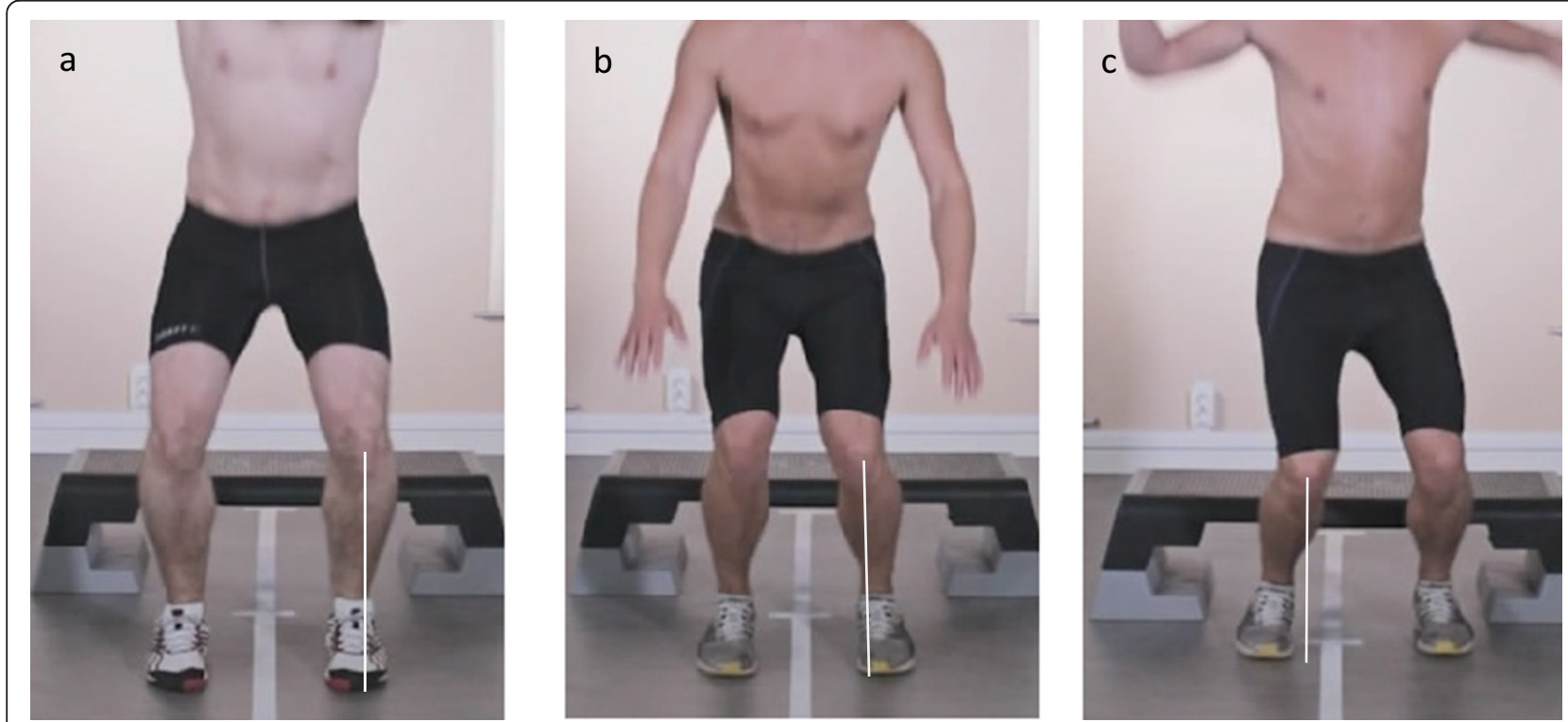

Figure 2 The position of the knee in relation to the foot during the drop jump. a) A score of 0 , representing good movement quality. b) A score of 1, representing fair movement quality. c) A score of 2, representing poor movement quality. 
Table 3 Intraclass correlation coefficient and 95\% confidence interval for inter-rater reliability for the knee position score assessment

\begin{tabular}{ll}
\hline Test & $\begin{array}{l}\text { ICC }(\mathbf{9 5} \% \mathrm{CI}) \\
\text { Knee assessment of injured leg }\end{array}$ \\
\hline Single-limb mini squat & $0.757(0.572-0.861)$ \\
Stair descending & $0.780(0.616-0.874)$ \\
Forward lunge & $0.716(0.278-0.868)$ \\
Drop jump & $0.939(0.885-0.967)$ \\
\hline
\end{tabular}

Differences in sensory function between subjects with good and poor movement quality

Women with a KMFP during stair descending had significantly worse vibration sense at MTP1 and MM than those with a KOFP (mean difference, -2.43 and $95 \% \mathrm{CI},-4.84$ to -0.02 for MTP1; mean difference, -2.98 and $95 \%$ $\mathrm{CI},-4.91$ to -0.84 for MM). Women with a KMFP during the forward lunge had significantly worse vibration sense at MM than those with a KOFP (mean difference, 2.69 and $95 \% \mathrm{CI},-4.63$ to -0.74 ), but no such differences were found in men (Table 6 and Figure 3a-b).

\section{Discussion}

These results indicate that worse kinesthetic acuity might be associated with KMFP during the drop jumpa test resembling a sports activity-in men with ACL injury. Worse vibration sense at the foot might be associated with KMFP during functional tasks resembling activities of daily living in women, but no such associations were observed in men.

Worse kinesthesia was related to a KMFP during the drop jump in men $\left(r_{s}=0.423\right)$ indicating that proprioceptive acuity contributes to movement quality at the knee during movements resembling sport-related activities. A similar, but non-significant, correlation coefficient was found in women $\left(r_{s}=0.469, p=0.106\right)$. To reach a significant correlation of $r_{s}=0.47$ would have required at least 18 subjects in the analysis [36], but we had only 13 women in the present study. Thus, the nonsignificant correlation in women might be due to too small of a sample. Moreover, in absolute values, although not reaching statistical significance, both women and men with KMFP during the drop jump had approximately $40 \%$ and $50 \%$ worse kinesthesia, respectively, than those with KOFP. This finding justifies further studies on the possible importance of proprioceptive acuity for medio-lateral knee position. Our hypothesis that the association between kinesthesia and movement quality would be more evident in women than in men was not confirmed because similar associations were observed for both genders. Because this is the first study on the association between sensory function and medio-lateral knee position during functional tasks, further studies are needed to confirm our findings.

Proprioceptive mechanoreceptors like the Golgi organ, free nerve endings, Pacinian corpuscles, and Ruffini endings are situated in the human ACL, capsule, menisci, and cartilage and are suggested to play an important role in the ability to detect movements and to sense where the joints are in relation to each other and to the environment $[37,38]$. These receptors are also reported to be involved in muscle stiffness regulation via the gamma muscle spindle circuit and are thus also important for dynamic joint stability [38]. Consequently, damage to the ACL might lead to deterioration in these afferent sensory signals. The results from the present study indicate that ACL-injured individuals with worse proprioceptive acuity might have reduced ability to control medio-lateral knee joint motion during the drop jump. Future studies will reveal if this is true also for individuals without knee injury but who are at high risk of sustaining a knee injury such as high-level athletes.

There has recently been an increased interest in measuring vibration sense in patients with knee injury and knee or hip osteoarthritis $[18,28,32]$. These studies show

Table 4 Sensory function and knee position score data during the functional tasks for women and men

\begin{tabular}{|c|c|c|c|}
\hline \multirow[b]{2}{*}{ Sensory test $(n=51)$} & Women $(n=23)$ & Men $(n=28)$ & \multirow[b]{2}{*}{ p-value } \\
\hline & \multicolumn{2}{|c|}{ Mean (SD) } & \\
\hline TDPM (degrees) & $2.43(1.38)$ & $1.91(0.87)$ & 0.105 \\
\hline VPT-MTP 1 (volts) & $5.04(2.33)$ & $5.27(2.88)$ & 0.754 \\
\hline VPT-MM (volts) & $7.14(2.57)$ & $8.77(4.41)$ & 0.124 \\
\hline VPT-MF (volts) & $12.17(3.66)$ & $14.0(4.05)$ & 0.098 \\
\hline Functional task & \multicolumn{2}{|c|}{ Median (quartiles, range) } & \\
\hline Single-limb mini squat & $1(0-1,0-2)(n=23)$ & $1(0-2,0-2)(n=28)$ & 0.116 \\
\hline Stair descending & $0(0-1,0-1)(n=22)$ & $0(0-1,0-2)(n=28)$ & 0.675 \\
\hline Forward lunge & $1(0-1,0-1)(n=19)$ & $1(0-1,0-2)(n=28)$ & 0.824 \\
\hline Drop jump & $0(0-1,0-2)(n=13)$ & $1(0-1,0-2)(n=23)$ & 0.662 \\
\hline
\end{tabular}

TDPM = threshold to detection of passive motion, VPT = vibration perception threshold, MTP1 = metatarsophalangeal joint 1, MM = medial malleolus, MF $=$ medial femoral condyle, bold text $=$ statistically significant difference $(p \leq 0.05)$. 
Table 5 Correlations between sensory function and medio-lateral knee position during the functional tasks

\begin{tabular}{|c|c|c|c|c|}
\hline \multirow{2}{*}{ Sensory test } & \multicolumn{4}{|c|}{ Medio-lateral knee position } \\
\hline & Single-limb mini squat & Stair descending & Forward lunge & Drop jump \\
\hline Women & $(n=23)$ & $(n=22)$ & $(n=19)$ & $(n=13)$ \\
\hline \multirow[t]{2}{*}{ TDPM (degrees) } & $r_{s}=0.344$ & $r_{s}=-0.288$ & $r_{s}=0.000$ & $r_{s}=0.469$ \\
\hline & $p=0.108$ & $p=0.194$ & $p=1.0$ & $p=0.106$ \\
\hline \multirow[t]{2}{*}{ VPT MTP1 (volts) } & $r_{s}=0.114$ & $r_{s}=0.453$ & $r_{s}=0.308$ & $r_{s}=-0.343$ \\
\hline & $p=0.603$ & $p=0.034$ & $p=0.199$ & $p=0.251$ \\
\hline \multirow[t]{2}{*}{ VPT MM (volts) } & $r_{5}=0.069$ & $r_{s}=0.626$ & $r_{s}=0.544$ & $r_{s}=-0.088$ \\
\hline & $p=0.756$ & $p=0.002$ & $p=0.016$ & $p=0.776$ \\
\hline \multirow[t]{2}{*}{ VPT MF (volts) } & $r_{s}=-0.092$ & $r_{s}=0.313$ & $r_{s}=0.409$ & $r_{s}=0.408$ \\
\hline & $p=0.675$ & $p=0.155$ & $p=0.082$ & $p=0.167$ \\
\hline Men & $(n=28)$ & $(n=28)$ & $(n=28)$ & $(n=23)$ \\
\hline \multirow[t]{2}{*}{ TDPM (degrees) } & $r_{s}=0.008$ & $r_{s}=0.338$ & $r_{s}=-0.030$ & $r_{s}=0.423$ \\
\hline & $p=0.969$ & $p=0.079$ & $p=0.878$ & $p=0.044$ \\
\hline \multirow[t]{2}{*}{ VPT MTP1 (volts) } & $r_{s}=-0.170$ & $r_{s}=-0.143$ & $r_{s}=-0.052$ & $r_{s}=-0.069$ \\
\hline & $p=0.388$ & $p=0.468$ & $p=0.794$ & $p=0.755$ \\
\hline \multirow[t]{2}{*}{ VPT MM (volts) } & $r_{s}=-0.115$ & $r_{s}=0.021$ & $r_{s}=0 .-232$ & $r_{s}=-0.162$ \\
\hline & $p=0.560$ & $p=0.917$ & $p=0.235$ & $p=0.461$ \\
\hline \multirow[t]{2}{*}{ VPT MF (volts) } & $r_{s}=-0.039$ & $r_{s}=0.121$ & $r_{s}=-0.237$ & $r_{s}=0.338$ \\
\hline & $p=0.844$ & $p=0.540$ & $p=0.224$ & $p=0.079$ \\
\hline
\end{tabular}

TDPM = threshold to detection of passive motion, VPT = vibration perception threshold, MTP1 = metatarsophalangeal joint $1, \mathrm{MM}=$ medial malleolus, MF = medial femoral condyle, $r_{s}=$ Spearman's rank correlation coefficient, bold text = statistically significant difference $(p \leq 0.05)$.

that patients with hip or knee osteoarthritis have an impaired sense of vibration both in the affected and adjacent joints [28,32]. However, no such impairments have yet been observed in subjects with meniscal or ACL injuries [18]. The possible associations between worse vibration sense and KMFP during stair descending and forward lunge in women in the present study could indicate some role of vibration sense for movement quality. No such relations were found in men, however, and the underlying reason for these gender differences needs further study along with the possible relevance of vibratory deficiencies in these patients.

In contrast to a previous study that reported that women with ACL injury were more prone to a KMFP compared to their male counterparts during a single leg squat [5], we found no gender-difference in medio-lateral knee position during the different functional tasks, including the single leg squat. There are several differences between that study and our study regarding outcomes and participants that might explain the contrasting findings. We assessed KMFP by visual observation in high-level athletes 9-16 months after injury, and all of our subjects were participating in a thorough neuromuscular training program at a sport rehabilitation clinic under the supervision of experienced physical therapists. In the previous study, Yamazaki et al. [5] used 3-D equipment to assess knee joint movement in recreational athletes at 33.5 months after injury without any rehabilitation training.

The underlying mechanisms for a KMFP in patients with ACL injury are still unclear. Trulsson et al. reported that a KMFP was more often present in patients with ACL injury than in healthy controls during different functional activities such as the forward lunge and a mini squat [4]. In another study, a higher degree of 3-D knee abduction was found in the subjects' ACL-injured knee compared to the non-injured knee during a single leg squat [5]. However, possible contributing factors for the medio-lateral knee position during functional tasks are poorly investigated in patients with ACL injury. The correlations found in the present study were mostly moderate and indicated some association between sensory function and medio-lateral knee position. However, future studies are warranted to evaluate the role of sensory function as well as other possible contributing sensorimotor and biomechanical factors for medio-lateral knee position in patients with knee injury. Such knowledge will help in the design of training programs for these patients.

There are some limitations in this study. Sixteen subjects were not able to perform all functional tasks, for 
Table 6 Sensory function in subjects with good and poor movement quality during the functional tasks

\begin{tabular}{|c|c|c|c|c|c|c|c|c|c|c|c|c|}
\hline \multirow{3}{*}{$\begin{array}{l}\text { Measures of } \\
\text { sensory function }\end{array}$} & \multicolumn{12}{|c|}{ Functional tasks } \\
\hline & \multicolumn{3}{|l|}{$\begin{array}{l}\text { Single-limb } \\
\text { mini squat }\end{array}$} & \multicolumn{3}{|c|}{ Stair descending } & \multicolumn{3}{|c|}{ Forward lunge } & \multicolumn{3}{|l|}{ Drop-jump } \\
\hline & $(n=7)$ & $(n=16)$ & & $(n=13)$ & $(n=9)$ & & $(n=8)$ & $(n=11)$ & & $(n=7)$ & $(n=6)$ & \\
\hline \multirow[t]{2}{*}{ Women } & Good & Poor & $\begin{array}{l}\text { Mean difference } \\
(95 \% \mathrm{Cl})\end{array}$ & Good & Poor & $\begin{array}{l}\text { Mean difference } \\
(95 \% \mathrm{Cl})\end{array}$ & Good & Poor & $\begin{array}{l}\text { Mean difference } \\
(95 \% \mathrm{Cl})\end{array}$ & Good & Poor & $\begin{array}{l}\text { Mean difference } \\
(95 \% \mathrm{Cl})\end{array}$ \\
\hline & Mean (SD) & Mean (SD) & & Mean (SD) & Mean (SD) & & Mean (SD) & Mean (SD) & & Mean (SD) & Mean (SD) & \\
\hline TDPM & $1.82(0.81)$ & $2.70(1.52)$ & $\begin{array}{l}-0.88 \\
(-2.16 \text { to } 0.39)\end{array}$ & $2.71(1.54)$ & $2.00(1.17)$ & $\begin{array}{l}0.71 \\
(-0.56 \text { to } 1.98)\end{array}$ & 2.59 (1.63) & $2.55(1.41)$ & $\begin{array}{l}0.48 \\
(-1.43 \text { to } 1.53)\end{array}$ & $1.96(1.25)$ & $2.92(1.77)$ & $\begin{array}{l}-0.95 \\
(-2.80 \text { to } 0.89)\end{array}$ \\
\hline VPT MTP1 & $4.29(1.11)$ & $5.37(2.67)$ & $\begin{array}{l}-1.01 \\
(-3.28 \text { to } 1.11)\end{array}$ & 4.05 (0.99) & $6.48(3.10)$ & $\begin{array}{l}-2.43 \\
(-4.84 \text { to }-0.02)\end{array}$ & $4.04(1.16)$ & $5.15(2.28)$ & $\begin{array}{l}-1.10 \\
(-2.97 \text { to } 0.75)\end{array}$ & $4.76(1.47)$ & $3.72(0.57)$ & $\begin{array}{l}1.04 \\
(-0.37 \text { to } 2.45)\end{array}$ \\
\hline VPT MM & $6.52(1.86)$ & $7.42(2.83)$ & $\begin{array}{l}-0.90 \\
(-3.39 \text { to } 1.55)\end{array}$ & $5.97(1.77)$ & $8.95(2.82)$ & $\begin{array}{l}-2.88 \\
(-4.91 \text { to }-0.84)\end{array}$ & $5.25(1.22)$ & $7.94(2.37)$ & $\begin{array}{l}-2.69 \\
(-4.63 \text { to }-0.74)\end{array}$ & $6.52(2.12)$ & $6.17(0.78)$ & $\begin{array}{l}0.36 \\
(-1.67 \text { to } 2.38)\end{array}$ \\
\hline VPT MF & $12.29(5.66)$ & $12.12(2.61)$ & $\begin{array}{l}0.16 \\
(-3.37 \text { to } 3.69)\end{array}$ & $11.43(4.13)$ & $13.59(2.61)$ & $\begin{array}{l}-2.15 \\
(-5.41 \text { to } 0.10)\end{array}$ & $10.33(4.17)$ & $13.67(3.31)$ & $\begin{array}{l}-3.33 \\
(-6.95 \text { to } 0.28)\end{array}$ & $10.62(4.86)$ & $13.50(3.06)$ & $\begin{array}{l}-2.88 \\
(-7.95 \text { to } 2.19)\end{array}$ \\
\hline Men & $(n=7)$ & $(n=21)$ & & $(n=19)$ & $(n=9)$ & & $(n=12)$ & $(n=16)$ & & $(n=11)$ & $(n=12)$ & \\
\hline TDPM & $1.86(0.86)$ & $1.93(0.89)$ & $\begin{array}{l}-0.07 \\
(-0.86 \text { to } 0.72)\end{array}$ & $1.66(0.58)$ & $2.44(1.14)$ & $\begin{array}{l}-0.79 \\
(-1.69 \text { to } 0.11)\end{array}$ & $1.98(1.03)$ & $1.86(0.75)$ & $\begin{array}{l}0.12 \\
(-0.57 \text { to } 0.81)\end{array}$ & $1.57(0.71)$ & $2.23(1.04)$ & $\begin{array}{l}-0.66 \\
(-1.44 \text { to } 0.12)\end{array}$ \\
\hline VPT MTP1 & $5.24(1.82)$ & $5.29(3.20)$ & $\begin{array}{l}-0.47 \\
\text { (-2.68 to } 2.59)\end{array}$ & 5.58 (3.35) & $4.63(1.46)$ & $\begin{array}{l}0.95 \\
(-1.46 \text { to } 3.37)\end{array}$ & $6.00(4.08)$ & $4,73(1.43)$ & $\begin{array}{l}1.27 \\
(-0.98 \text { to } 3.52)\end{array}$ & $6.12(4.26)$ & $4.86(1.33)$ & $\begin{array}{l}1.29 \\
(-1.43 \text { to } 3.95)\end{array}$ \\
\hline VPT MM & $7.81(1.92)$ & 9.09 (4.53) & $\begin{array}{l}-1.29 \\
(-5.28 \text { to } 2.71)\end{array}$ & $9.00(5.16)$ & $8.29(2.31)$ & $\begin{array}{l}0.71 \\
(-3.02 \text { to } 4.43)\end{array}$ & 9.94 (6.33) & 7.89 (1.91) & $\begin{array}{l}2.05 \\
(-1.38 \text { to } 3.93)\end{array}$ & $9.94(6.53)$ & $8.36(2.31)$ & $\begin{array}{l}1.58 \\
(-2.59 \text { to } 5.75)\end{array}$ \\
\hline VPT MF & 12.90 & 14.36 & $\begin{array}{l}-1.46 \\
(-5.12 \text { to } 2.20)\end{array}$ & $13.77(4.32)$ & $14.48(3.62)$ & $\begin{array}{l}-0.71 \\
(-4.13 \text { to } 2.71)\end{array}$ & $14.92(4.66)$ & $13.31(3.63)$ & $\begin{array}{l}1.60 \\
(-1.57 \text { to } 4.78)\end{array}$ & $14.06(4.84)$ & $14.36(3.94)$ & $\begin{array}{l}-0.30 \\
(-4.17 \text { to } 3.57)\end{array}$ \\
\hline
\end{tabular}

TDPM = threshold to detection of passive motion, VPT = vibration perception threshold, MTP1 = metatarsophalangeal joint 1, MM = medial malleolus, MF = medial femoral condyle, bold text = statistically significant difference $(p \leq 0.05)$. 


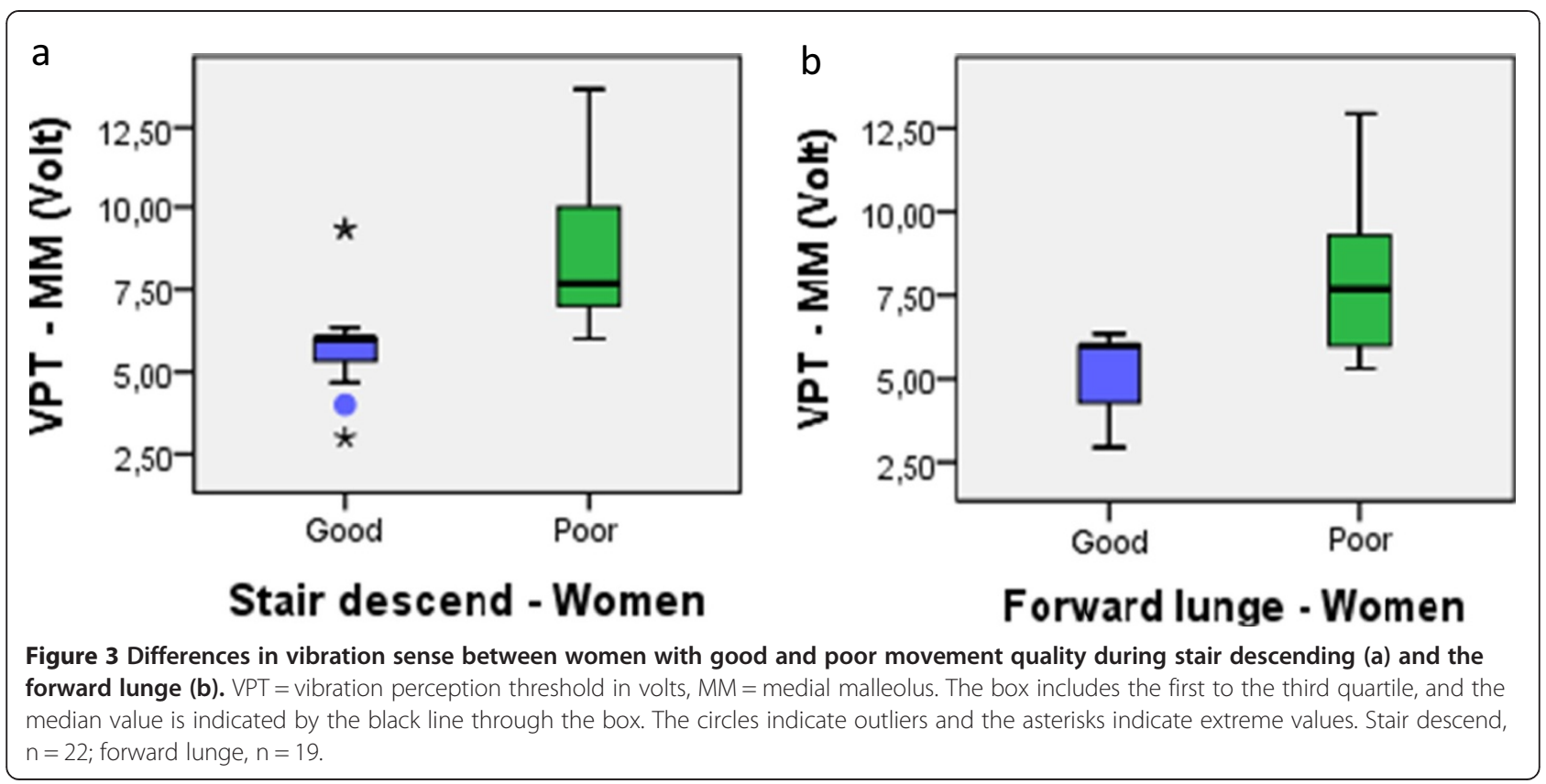

example, 10 out of the 23 women were not able to execute the drop jump task. This resulted in a small sample for the drop jump in women and a small number of subjects in the good and poor knee-position groups during all functional tasks, and this might have contributed to the lack of significant findings. This study had a cross-sectional design and we are, therefore, unable to draw any conclusions regarding causal relationships. Moreover, all subjects were athletes competing at a high level before they were injured, primarily soccer or team handball, and our results might not be generalizable to a recreational or sedentary population. Finally, because this was an exploratory study we did not correct for multiple comparisons. Thus there is a risk that some of the findings in this study are due to chance, and further studies are needed to confirm our results.

\section{Conclusion}

Our findings suggest that impaired proprioceptive acuity, measured as TDPM, might be associated with a medial position of the knee relative to the foot during the drop jump in men with ACL injury. Decreased vibration sense at the foot and the knee might be associated with worse KMFP in women. However, further studies are needed to confirm these results and to determine the relative contribution of proprioception, vibration sense, and other aspects of sensorimotor function on KMFP.

\section{Competing interests}

The authors declare that they have no competing interests.

\section{Authors' contributions}

AC contributed to the design of the study, was responsible for acquiring the data, was responsible for the analysis and interpretation of the data, and was in charge of writing the manuscript. EA contributed to the conception and design of the study, contributed in analysis and interpretation of data, contributed in writing the manuscript, and provided feedback on drafts of this paper. Both authors read and approved the final manuscript.

\section{Acknowledgments}

We thank Jenny Älmqvist, MSc, and Gustav Nilsson, MSc_-physical therapists at "Kulan Idrottsskadecentrum" in Malmö—for assessing and scoring the patients' movement quality.

\section{Funding}

This research was funded by the Swedish Research Council (2009-1447), the Crafoord Foundation, Skåne Regional Council, the Swedish Rheumatism Association, the Swedish National Centre for Research in Sports, and the Faculty of Medicine of Lund University.

Received: 3 June 2014 Accepted: 9 December 2014

Published: 13 December 2014

\section{References}

1. Thomee R, Kaplan Y, Kvist J, Myklebust G, Risberg MA, Theisen D, Tsepis E, Werner S, Wondrasch B, Witvrouw E: Muscle strength and hop performance criteria prior to return to sports after $\mathrm{ACL}$ reconstruction. Knee Surg Sports Traumatol Arthrosc 2011, 19(11):1798-1805.

2. Ardern $\mathrm{CL}$, Webster KE, Taylor NF, Feller JA: Return to sport following anterior cruciate ligament reconstruction surgery: a systematic review and meta-analysis of the state of play. Br J Sports Med 2011, 45(7):596-606.

3. Trulsson A, Roos EM, Ageberg E, Garwicz M: Relationships between postural orientation and self reported function, hop performance and muscle power in subjects with anterior cruciate ligament injury. BMC Musculoskelet Disord 2010, 11:143.

4. Trulsson A, Garwicz M, Ageberg E: Postural orientation in subjects with anterior cruciate ligament injury: development and first evaluation of a new observational test battery. Knee Surg Sports Traumatol Arthrosc 2010, 18(6):814-823.

5. Yamazaki J, Muneta T, Ju YJ, Sekiya I: Differences in kinematics of single leg squatting between anterior cruciate ligament-injured patients and healthy controls. Knee Surg Sports Traumatol Arthrosc 2010, 18(1):56-63.

6. Horak FB: Postural orientation and equilibrium: what do we need to know about neural control of balance to prevent falls? Age Ageing 2006 35 Suppl 2:ii7-ii11. 
7. Ageberg E, Bennell KL, Hunt MA, Simic M, Roos EM, Creaby MW: Validity and inter-rater reliability of medio-lateral knee motion observed during a single-limb mini squat. BMC Musculoskelet Disord 2010, 11:265.

8. Örtqvist M, Mostrom EB, Roos EM, Lundell P, Janarv PM, Werner S, Broström EW: Reliability and reference values of two clinical measurements of dynamic and static knee position in healthy children. Knee Surg Sports Traumatol Arthrosc 2011, 19(12):2060-2066.

9. Hewett TE, Myer GD, Ford KR, Heidt RS Jr, Colosimo AJ, McLean SG, van den Bogert AJ, Paterno MV, Succop P: Biomechanical measures of neuromuscular control and valgus loading of the knee predict anterior cruciate ligament injury risk in female athletes: a prospective study. Am J Sports Med 2005, 33(4):492-501.

10. Alentorn-Geli E, Myer GD, Silvers HJ, Samitier G, Romero D, Lazaro-Haro C, Cugat R: Prevention of non-contact anterior cruciate ligament injuries in soccer players. Part 1: Mechanisms of injury and underlying risk factors. Knee Surg Sports Traumatol Arthrosc 2009, 17(7):705-729.

11. Engelen-van Melick N, van Cingel RE, Tijssen MP, der Sanden MW N-v Assessment of functional performance after anterior cruciate ligament reconstruction: a systematic review of measurement procedures. Knee Surg Sports Traumatol Arthrosc 2012, 4:869-879.

12. Salmon $L$, Russell $V$, Musgrove T, Pinczewski L, Refshauge $K$ : Incidence and risk factors for graft rupture and contralateral rupture after anterior cruciate ligament reconstruction. Arthroscopy 2005, 21(8):948-957.

13. Ekegren CL, Miller WC, Celebrini RG, Eng JJ, Macintyre DL: Reliability and validity of observational risk screening in evaluating dynamic knee valgus. J Orthop Sports Phys Ther 2009, 39(9):665-674

14. Munro A, Herrington L, Carolan M: Reliability of 2-dimensional video assessment of frontal-plane dynamic knee valgus during common athletic screening tasks. J Sport Rehabil 2012, 21(1):7-11.

15. Gokeler A, Benjaminse A, Hewett TE, Lephart SM, Engebretsen L, Ageberg E, Engelhardt M, Arnold MP, Postema K, Otten E, Dijkistra PU: Proprioceptive deficits after ACL injury: are they clinically relevant? Br J Sports Med 2011, 3:180-192.

16. Ageberg E, Flenhagen J, Ljung J: Test-retest reliability of knee kinesthesia in healthy adults. BMC Musculoskelet Disord 2007, 8:57.

17. Shumway-Cook AWMH: Constraints on Motor Control: An Overview of Neurologic Impairments. In Motor Control - Translating Research Into Clinical Practice. Philadelphia: Lippincott Williams \& Wilkins; 2007:100-135.

18. Thorlund JB, Shakoor N, Ageberg E, Sandal LF, Block JA, Roos EM: Vibratory perception threshold in young and middle-aged patients at high risk of knee osteoarthritis compared to controls. Arthritis Care Res (Hoboken) 2012, 64(1):144-148.

19. Roberts D, Ageberg E, Andersson G, Fridén T: Clinical measurements of proprioception, muscle strength and laxity in relation to function in the ACL-injured knee. Knee Surg Sports Traumatol Arthrosc 2007, 15(1):9-16.

20. Katayama M, Higuchi H, Kimura M, Kobayashi A, Hatayama K, Terauchi M, Takagishi K: Proprioception and performance after anterior cruciate ligament rupture. Int Orthop 2004, 28(5):278-281.

21. Ageberg $E$, Roberts $D$, Holmstrom E, Fridén T: Balance in single-limb stance in patients with anterior cruciate ligament injury: relation to knee laxity, proprioception, muscle strength, and subjective function. Am J Sports Med 2005, 33(10):1527-1535.

22. Nagai T, Sell TC, House AJ, Abt JP, Lephart SM: Knee proprioception and strength and landing kinematics during a single-leg stop-jump task. J Athl Train 2013, 48(1):31-38.

23. Beaulieu ML, Lamontagne $M, X u$ L: Lower limb muscle activity and kinematics of an unanticipated cutting manoeuvre: a gender comparison. Knee Surg Sports Traumatol Arthrosc 2009, 17(8):968-976.

24. Gehring D, Melnyk M, Gollhofer A: Gender and fatigue have influence on knee joint control strategies during landing. Clin Biomech (Bristol, Avon) 2009, 24(1):82-87.

25. Graci V, Van Dillen LR, Salsich GB: Gender differences in trunk, pelvis and lower limb kinematics during a single leg squat. Gait Posture 2012, 36(3):461-466

26. Sigward SM, Pollard CD, Havens KL, Powers CM: Influence of sex and maturation on knee mechanics during side-step cutting. Med Sci Sports Exerc 2012, 44(8):1497-1503.

27. Willson JD, Petrowitz I, Butler RJ, Kernozek TW: Male and female gluteal muscle activity and lower extremity kinematics during running. Clin Biomech (Bristol, Avon) 2012, 27(10):1052-1057.
28. Shakoor N, Lee KJ, Fogg LF, Block JA: Generalized vibratory deficits in osteoarthritis of the hip. Arthritis Rheum 2008, 59(9):1237-1240.

29. Bloom S, Till S, Sonksen P, Smith S: Use of a biothesiometer to measure individual vibration thresholds and their variation in 519 non-diabetic subjects. Br Med J (Clin Res Ed) 1984, 288(6433):1793-1795.

30. Frenette $B$, Mergler D, Ferraris J: Measurement precision of a portable instrument to assess vibrotactile perception threshold. Eur J Appl Physiol Occup Physiol 1990, 61(5-6):386-391.

31. Ageberg E, Björkman A, Rosen B, Lundborg G, Roos EM: Principles of brain plasticity in improving sensorimotor function of the knee and leg in healthy subjects: a double-blind randomized exploratory trial. BMC Musculoskelet Disord 2009, 10:99.

32. Shakoor N, Agrawal A, Block JA: Reduced lower extremity vibratory perception in osteoarthritis of the knee. Arthritis Rheum 2008, 59(1):117-121.

33. Pfeifer $\mathrm{K}$, Banzer $\mathrm{W}$ : Motor performance in different dynamic tests in knee rehabilitation. Scand J Med Sci Sports 1999, 9(1):19-27.

34. Alkjaer T, Simonsen EB, Peter Magnusson SP, Aagaard H, Dyhre-Poulsen P: Differences in the movement pattern of a forward lunge in two types of anterior cruciate ligament deficient patients: copers and non-copers. Clin Biomech (Bristol, Avon) 2002, 17(8):586-593.

35. Powell JW, Barber-Foss KD: Sex-related injury patterns among selected high school sports. Am J Sports Med 2000, 28(3):385-391.

36. Bland M: An Introduction To Medical Statistics, Volume 3. New York: Oxford University Press Inc; 2000

37. Johansson H, Sjölander P, Sojka P: A sensory role for the cruciate ligaments. Clin Orthop Relat Res 1991, 268:161-178.

38. Johansson $\mathrm{H}$ : Role of knee ligaments in proprioception and regulation of muscle stiffness. J Electromyogr Kinesiol 1991, 1(3):158-179.

doi:10.1186/1471-2474-15-430

Cite this article as: Cronström and Ageberg: Association between sensory function and medio-lateral knee position during functional tasks in patients with anterior cruciate ligament injury. BMC Musculoskeletal Disorders 2014 15:430.

\section{Submit your next manuscript to BioMed Central and take full advantage of:}

- Convenient online submission

- Thorough peer review

- No space constraints or color figure charges

- Immediate publication on acceptance

- Inclusion in PubMed, CAS, Scopus and Google Scholar

- Research which is freely available for redistribution 